\title{
LOS DERECHOS ECONÓMICO-SOCIALES Y EL PRINCIPIO DE IGUALDAD EN LA TEORÍA DE LOS DERECHOS DE ROBERT ALEXY*
}

\author{
Liborio L. Hierro \\ Universidad Autónoma de Madrid
}

RESUMEN. El objeto de estas páginas es analizar las presuntas diferencias entre los derechos individuales, civiles y políticos, y los derechos económicos, sociales y culturales y discutir si estas diferencias se consolidan o se disuelven en la reconstrucción teórica propuesta por Robert Alexy. Tras analizar y rechazar las cinco diferencias que con más frecuencia se alegan entre los derechos de una y otra clase así como de presentar la teoría de Alexy sobre los derechos económico sociales concluyo, con Holmes y Sunstein, que «todos los derechos jurídicamente protegidos son necesariamente derechos a acciones positivas" y sostengo que Alexy no llega a extraer todas las consecuencias que de ello se derivan. La principal es que hemos de abandonar la distinción histórico ideológica entre derechos individuales, civiles y políticos, de un lado, y derechos económicos, sociales y culturales, del otro.

Palabras clave: Robert Alexy, derechos económicos, sociales y culturales.

ABSTRACT. The object of this article is to analyse the alleged differences between individual, civil and political rights and economic, social and cultural rights and to discuss whether these differences are either reinforced or undermined by Robert Alexy's theoretical reconstruction. After discussing and rejecting the most frequently alleged five differences between rights of both kinds and presenting Alexy's theory on economic and social rights, I conclude, with Holmes and Sunstein, that "all legally enforced rights are necessarily positive rights» and hold that Alexy does not extract all the consequences deriving from this fact. The most important consequence is that we need to abandon the historical-ideological distinction between individual, civil and political rights on the one hand, and economic, social and cultural rights, on the other.

Keywords: Robert Alexy, economic, social and cultural rights.

* Este trabajo se enmarca en el Proyecto SEJ2005-08885/JURI (Derechos, Justicia y Globalización) financiado por la Dirección General de Investigación del Ministerio de Educación y Ciencia. 


\section{INTRODUCCIÓN}

L

os Pactos sobre Derechos Humanos de $1966^{1}$ vinieron a consolidar la división histórica de los derechos humanos en dos grandes categorías, la de los derechos civiles y políticos (a la que históricamente suele denominarse «primera generación») y la de los derechos económicos, sociales y culturales (a la que paralelamente se denomina «segunda generación») ${ }^{2}$. En algún modo la consolidación de esta dualidad se hacía eco del contexto ideológico de la guerra fría 3 .

Para el pensamiento liberal la primera categoría incluía los derechos auténticos («iura proprie aut stricte dicta», parafraseando a GROCIO) a los que cabía entender como derechos universales o de todos los seres humanos, frente a los derechos sociales que serían derechos específicos de los trabajadores; como derechos absolutos o contra todos, frente a los derechos sociales que serían derechos relativos o frente a un obligado determinado (el Estado, el empresario, etc.); como derechos definitivos en cuanto su mero enunciado define su contenido, frente a los derechos sociales cuyo contenido no quedaría establecido por su mero enunciado sino que requeriría una cierta forma institucional; como derechos inmediatamente eficaces contra el Estado, frente a los derechos sociales cuya eficacia dependería de la instrumentación de medios costosos por el propio Estado; y, consecuentemente con todo ello, como derechos justiciables, frente a la falta de justiciabilidad característica de los derechos sociales que sólo la alcanzarían en la medida en que el legislador hubiera establecido acciones concretas en su protección.

Para el pensamiento socialista la segunda generación era la que incluía los derechos auténticos pues éstos eran los derechos propiamente universales en cuanto requeridos para su realización personal por las grandes masas de obreros y campesinos, frente a los derechos individuales como derechos específicos de los burgueses propietarios; eran los derechos sustantivos en cuanto sólo su satisfacción podía liberar a cada individuo de su alienación, frente a los derechos liberales que tenían un mero carácter formal para todo aquel que carecía de autonomía económica; eran los derechos primarios en cuanto sólo una vez satisfechos ellos podía disfrutarse de los derechos individuales que, por tanto, eran derechos derivados; y eran los derechos inmediatos que debían ser satisfechos directamente por la organización política, frente a los derechos civiles y políticos cuyo auténtico disfrute por todas las personas sólo podía alcanzarse realmente por la previa mediación de aquéllos ${ }^{4}$.

${ }^{1}$ Como es sabido, el Pacto Internacional sobre Derechos Económicos, Sociales y Culturales y el Pacto Internacional sobre Derechos Civiles y Políticos fueron adoptados por Resolución 2200 A (XXI) de la Asamblea General de las Naciones Unidas el 16 de diciembre de 1966. El primero de ellos entró en vigor el 3 de enero de 1976 y el segundo el 23 de marzo de 1976.

2 En contra, G. PECES BARBA (1999: 59 y 61) que distingue una primera generación de derechos individuales y civiles, una segunda generación de derechos políticos y una tercera generación de derechos económicos, sociales y culturales. No me parece que esta distinción entre primera y segunda generación tenga suficiente apoyo histórico aunque coincida con la distinción originalmente propuesta por T. H. MARSHALL en 1959 (en sus conferencias publicadas bajo el título Citizenship and Social Class) (vid. Ruiz Miguel, 1994: 651 y EIDE, 2001: 13).

${ }^{3}$ Sobre el contexto socio-ideológico de la Declaración Universal de 1948 es muy esclarecedor el análisis de A. CASSESE (1991: 36-54). Vid. también, sobre el alcance ideológico de la distinción, RuIZ MigUEL, 1994: 653 y PÉREZ LuÑo, 2003: 86-93.

${ }^{4}$ Por todos, E. BLOCH (1980: XI): «No hay una instauración verdadera de los derechos del hombre sin poner fin a la explotación, no hay verdadero término de la explotación sin la instauración de los derechos del 
Los unos y los otros consideraban «auténtica» una de ambas categorías de los derechos y miraban indulgentemente la contraria. Según cada una de estas concepciones los derechos individuales o los derechos sociales, respectivamente, constituían los derechos inmediatamente exigibles al Estado mientras que los otros, respectivamente los derechos sociales y los derechos individuales, eran los que se alcanzarían en un estado de cosas deseable una vez superada, respectivamente, la situación de escasez o la situación de explotación.

Puede resultar sorprendente que una distinción surgida y consolidada por factores históricos tan contingentes penetrase tan profundamente como lo ha hecho en la Teoría de los Derechos contemporánea, pero no cabe duda de que lo ha hecho. Todavía, tanto en el pensamiento filosófico jurídico como en la doctrina jurídico constitucional, la división entre estas dos categorías de derechos humanos parece constituir un problema aunque, dado el desenlace de la guerra fría, el problema parece haberse reducido a si los derechos sociales son o no son auténticos derechos. Aquellas diferencias han tomado, pues, carta de naturaleza en la teoría y todavía para un gran número de autores los derechos sociales parecen ser meras aspiraciones políticas o — como señala Luis PRIETO— «en el mejor de los casos, derechos disminuidos o en formación» (PRIETO, 1998: 97).

El objeto de estas páginas es analizar las presuntas diferencias entre los derechos individuales, civiles y políticos, y los derechos económicos, sociales y culturales —a los que, por simple economía semántica, llamaré respectivamente «derechos individuales» $\mathrm{y}$ «derechos económico-sociales» ${ }^{5}-\mathrm{y}$ discutir si estas diferencias se consolidan o se disuelven en la reconstrucción teórica propuesta por Robert ALEXY ${ }^{6}$.

hombre... El rasgo fundamental — sobre todo del Derecho Natural clásico— es viril, una insistencia en la facultas agendi de hombres ya desalienados en la norma agendi de una comunidad finalmente desalienada». Vid. especialmente el capítulo 19 (pp. 156-183) donde BLOCH desarrolla la idea de ENGELS de que «en relación con la Revolución francesa, los derechos del hombre y el Derecho natural burgués: "Los proletarios toman a la burguesía por su palabra”».

La generalización que hago sobre el pensamiento socialista no pretende corresponder a la posición del marxismo ortodoxo. La posición de MARX sobre los derechos humanos, desde La Cuestión Judía (1844) hasta El Capital (1867) y las obras posteriores, adolece de una permanente ambigüedad como ha puesto de relieve la monografía de M. ATIENZA (1983). MARX nunca llegó a desprenderse de la idea de que los derechos humanos estaban ligados, como ideología y como institución, al Estado burgués, de tal forma que la superación del Estado burgués implicaba la superación de los derechos humanos aunque, al mismo tiempo, la sociedad comunista supondría la realización de la libertad y la igualdad (vid. ATIENZA, ibidem, passim y en particular pp. 5157 y 220-224). ATIENZA concluye con razón que «la insuficiencia de la postura de MARX en relación con los derechos humanos se debe, en mi opinión, a que sólo se interesó por ellos y los defendió por razones políticas, no éticas» (ibidem, 279).

${ }^{5}$ Las convenciones académicas más extendidas suelen distinguir entre «derechos individuales, civiles y políticos» y «derechos económicos, sociales y culturales», con una clara influencia del lenguaje de los Pactos de 1966. Algunos autores abrevian la distinción para hablar de «derechos individuales» frente a «derechos sociales» (ABramovich y COURTIS, 2002: 120; CASCAJO, 1988: 16; LAPORTA, 2004: 298; PECEs BARBA, 1999: 7 y passim; PRIETO, 1998: 71). Otros, como Carl WeLLMAN, distinguen entre derechos humanos (contra todos) y derechos cívicos (contra el Estado al que se pertenece, entre los que se situarían los «derechos económicos» como derechos especiales) (WeLLMAN, 1997: 24-25 y 115). Utilizaré en lo sucesivo la denominación «derechos económico-sociales», aunque me parece todavía bastante vaga, por ser —según creo— suficientemente comprensiva pero obvio es decir que con ello me referiré, genéricamente, a los derechos económicos, sociales y culturales en la forma en que se declaran, por ejemplo, en el respectivo Pacto de 1966. En todo caso la denominación tiene aquí un mero carácter provisional ya que, como pretendo argumentar, la distinción me parece incorrecta. 


\section{SUPUESTAS DIFERENCIAS ENTRE LOS DERECHOS INDIVIDUALES Y LOS DERECHOS ECONÓMICO-SOCIALES}

Una muy extendida concepción de los derechos económico-sociales viene asumiendo que entre ellos y los derechos individuales, civiles y políticos existen, además de una diferente génesis histórica, una serie de diferencias estructurales que obligan a tratarlos como dos categorías de derechos irreductiblemente distintas ${ }^{7}$. Esa serie de diferencias suelen referirse al sujeto titular de los derechos, a su contenido y a las posibilidades de protección. Esa serie de diferencias se esgrimen hoy generalmente para contraponer una supuesta perfección de los derechos individuales frente a una supuesta imperfección de los derechos económico-sociales. Estos últimos serían inevitablemente derechos imperfectos bien por su imposible universalidad, bien por su contenido indefinido, bien por su necesariamente imperfecta protección ${ }^{8}$.

Creo que esta concepción, por extendida que esté, sigue obedeciendo a los intereses y prejuicios que retrasaron la aparición histórica de los derechos sociales y que no resiste un análisis teórico libre de tales prejuicios. Trataré de argumentarlo analizando algunas de las características diferenciales más generalmente invocadas y demostrando que no son predicables sólo de los derechos económico-sociales. Mi argumento, por tanto, no trata de demostrar que los derechos económico-sociales no tengan las imper-

Por decirlo ahora brevemente: entre los derechos individuales, civiles y políticos existen numerosos derechos de pretensión cuya satisfacción requiere una prestación «económica» (esto es, costosa) y entre los derechos económicos, sociales y culturales existen algunas libertades, inmunidades y potestades cuya satisfacción sería, en principio, gratuita (al menos, tan gratuita como la de cualquier otra libertad, inmunidad o potestad). La protección de los derechos siempre es, en todo caso, costosa. Si la protección forma o no forma parte del derecho mismo es una cuestión a discutir; si la protección forma parte del derecho, todos los derechos son costosos; si la protección no forma parte del derecho, entonces cabe distinguir entre derechos gratuitos y derechos costosos. Aunque ahora no me ocuparé de ello, habría que añadir que la suposición de que los derechos cuya satisfacción primaria estriba en una abstención de otro u otros son derechos gratuitos es una suposición vulgar que queda desmentida por el Teorema de Coase (es decir: las meras abstenciones también pueden representar, desde el punto de vista económico, un coste).

${ }^{6}$ Parece conveniente recordar que la impresionante reconstrucción teórica propuesta por ALEXY (1993) no tiene como objeto los derechos humanos en el plano moral o filosófico político sino los derechos fundamentales contenidos en la Ley Fundamental de Bonn, lo que permite considerarla una «dogmática» especial, aunque sin duda apoyada en un potente análisis filosófico.

7 Tanto en el pensamiento filosófico jurídico como en la doctrina jurídico constitucional, la división entre estas dos categorías de derechos humanos parece constituir un problema aunque el problema parece haberse reducido hoy a si los derechos sociales son o no son auténticos derechos. Sobre esta cuestión podemos encontrar cuatro respuestas: 1) que los llamados derechos económico-sociales no son en ningún sentido auténticos derechos subjetivos sino simplemente principios u objetivos políticos; 2) que los derechos económico-sociales no son auténticos derechos subjetivos jurídicos pero son auténticos derechos subjetivos en otro sentido (en sentido político; F. ATRIA, 2005, passim); 3) que los derechos económico-sociales son auténticos derechos subjetivos cuya protección suscita problemas específicos y pueden ser jurídicamente implementados encontrando las técnicas específicas adecuadas (ABRAMOVICH y COURTIS, 2002, passim; y 4) que los derechos económico-sociales son auténticos derechos subjetivos y no suscitan ningún problema específico que no hayan suscitado los derechos individuales y políticos y, en consecuencia, que las técnicas de satisfacción y protección de los derechos no pasan por la distinción entre estos dos tipos de derechos. Esta última es la que trato aquí de argumentar.

${ }^{8}$ El análisis que voy a presentar es deudor, principalmente, de lo que WeLLMAN señala como «four interrelated difficulties in the theory of economic rights» (que son: la dificultad de la escasez de recursos, la dificultad de especificar el contenido, la dificultad de identificar a los segundos obligados y la dificultad de localizar el título que confiere el Derecho) (WELLMAN, 1997: 105-116) y CASCAJO denomina «aporías de los derechos sociales» (que incluyen: su carácter relativo, su carácter gradual, su carácter dinámico, su debilidad orgánica y su carácter no-justiciable) (CASCAJO, 1988: 30-34). 
fecciones que se les imputan sino de demostrar que tales supuestas imperfecciones las tienen también los llamados «derechos individuales»?.

Esas características diferenciales, aunque expresadas en formas distintas, pueden reducirse a las cinco siguientes: 1) los derechos económico-sociales no son universales, sino particulares de cierto tipo de sujetos; 2) los derechos económico-sociales no son absolutos (erga omnes) sino relativos a cierto tipo de relación social; 3 ) los derechos económico-sociales no son definitivos sino que requieren para su actualización la mediación de una cierta organización de las instituciones públicas; 4) los derechos económico-sociales no son gratuitos ni baratos sino que son derechos caros cuya satisfacción requiere llevar a cabo cuantiosas inversiones públicas; 5) los derechos económico-sociales no son, en consecuencia, justiciables. De ello derivan los que así piensan que en los derechos económico-sociales predomina la denominada dimensión objetiva frente a la dimensión subjetiva o, dicho en términos más claros: que los llamados derechos económico-sociales son buenas guías para el legislador pero no son derechos subjetivos.

\subsection{Sobre el pretendido carácter particular («los derechos económico-sociales no son derechos universales»)}

Si los derechos humanos tienen que ser derechos universales y la universalidad de los derechos consistiera en que el derecho en cuestión debe ser actualmente disfrutado por todos los seres humanos, sea cual sea la ocasión en que se encuentren, entonces algunos derechos individuales clásicos no son, ni han sido nunca, universales y, en consecuencia, no serían derechos humanos. Las declaraciones de derechos afirman categóricamente que los hombres tienen, por el mero hecho de ser seres humanos, ciertos derechos entre los que, por ejemplo, se encuentran el derecho a la propiedad y el derecho a la resistencia a la opresión. Naturalmente, los afortunados seres humanos que no estén en la situación de oprimidos no disfrutan, o no pueden ejercer, el importante derecho de resistirse a la opresión, aunque nadie ha dudado de que eso no resta universalidad alguna al derecho cuyo significado moral normativo es que cualquier ser humano que se encuentre en la ocasión de estar oprimido tiene el derecho a resistirse. Más llamativo es el derecho de propiedad. Predicado como derecho natural de todo ser humano, nadie pretendió que el mero hecho de ser un ser humano concediese a nadie el derecho a ser propietario de algo (nunca, por lo que yo sé, el derecho de propiedad ha sido concebido como una pretensión). Lo único que le concedía era el derecho a poder serlo siempre y cuando se encontrase en la afortunada ocasión denominada «modo de adquirir la propiedad», ocasión detalladamente construida por la tradición jurídica liberal y más definitivamente establecida por los códigos civiles. Cualquier persona, pues, se convierte en

\footnotetext{
${ }_{9}$ Omitiré, por entenderlo trivial, el argumento de que entre los llamados «derechos económicos, sociales y culturales» quedaron incluidos, por razones meramente históricas, derechos típicamente liberales como, por ejemplo, la libertad de asociación obrera, la no discriminación en el puesto de trabajo o la libertad de crear centros docentes (respectivamente, en el Pacto Internacional de Derechos económicos, sociales y culturales: artículo 8.1.a), artículo 7.c) y artículo 13.4. Mis argumentos coinciden en términos generales con los de RuIz MIGUEL, 1994, passim, con la única diferencia de que él los organiza en torno a los presuntos caracteres de absolutidad, universalidad e inalienabilidad de los derechos humanos; coinciden también sustancialmente con el excelente análisis de V. ABRAmovich y C. CourTis, 2002 (especialmente en el capítulo 1, pp. 19-64).
} 
propietario si ocupa un bien que sea apropiable por su naturaleza y que carezca de dueño, o bien si se lo concede el legislador, o bien si se lo regalan, o bien si se lo dejan en herencia o bien si lo adquiere por consecuencia de cierto contrato mediante la tradición ${ }^{10}$. Obvio es decir que los millones de personas que, durante mucho tiempo y aun ahora, no han ocupado bienes ocupables que carezcan de dueño, no se han beneficiado de la benevolencia del legislador, no han heredado (normalmente, porque la situación de sus ascendientes era tan paupérrima como la suya), y no han tenido ocasión de formalizar un contrato que les proporcione algo más que un salario de subsistencia, son millones de personas que - después de cenar- no tienen propiedad alguna. El derecho natural universal a la propiedad no es otra cosa que el derecho universal a ser propietario si uno se encuentra en la ocasión de serlo. Entonces, y sólo entonces, la legislación moderna despliega un amplio sistema de libertades, potestades e inmunidades que configuran el supuestamente universal derecho de propiedad ${ }^{11}$.

Parece fácil concluir que el que ciertos derechos universales se prediquen de los seres humanos que se encuentran en ciertas ocasiones, o que su disfrute dependa de una cierta configuración ocasional, no es un óbice a su pretendida universalidad. En todo caso no es una característica exclusiva de los derechos económico-sociales el que se trate de derechos que se predican del ser-humano-que-trabaja o del ser-humano-que-carece o, dicho en la otra forma, que su disfrute depende de cierta situación laboral o de cierta situación de carencia ${ }^{12}$.

\subsection{Sobre el pretendido carácter relativo («los derechos económico-sociales no son derechos absolutos o erga omnes») ${ }^{13}$}

Si los derechos humanos tienen que ser derechos absolutos y el carácter absoluto de los derechos consistiera en que el titular puede esgrimir su derecho contra todos y todos están obligados a realizar alguna acción o a observar alguna abstención para sa-

\footnotetext{
${ }^{10}$ Estas referencias recogen los llamados «modos de adquirir la propiedad» según el artículo 609 del Código Civil español.

${ }^{11}$ El artículo 17 de la Declaración de los Derechos del Hombre y del Ciudadano, aprobada por la Asamblea Nacional francesa en 1789 e incorporada a la Constitución revolucionaria de 1791, sólo decía al respecto que «siendo la propiedad un derecho inviolable y sagrado, nadie puede ser privado de ella sino cuando la necesidad pública, legalmente constatada, lo exige claramente y con la condición de una indemnización justa y previa». La Declaración jacobina de 1793 fue más explícita en su redacción —lo que RITCHIE considera más adecuado a la mentalidad de un jurista inglés (RITCHIE, 1924: 265) — y dice en su artículo 16 que «el derecho de propiedad es el que pertenece a todo ciudadano de gozar y de disponer, de acuerdo con su criterio, de sus bienes, de sus ganancias, del fruto de su trabajo y de su industria». Este notable esfuerzo definitorio, aunque permite atribuir a todos los hombres la propiedad sobre el fruto de su trabajo, sigue sin resolver cuándo los bienes, las ganancias y las industrias son «suyas». En todo caso - como señalan HOLMES y SuNSTEIN— «the definition, assignment, interpretation, and protection of property rights is a government service that is delivered to those who currently own property, while being funded out of general revenues extracted from the public at large» (HOLMES y SUNSTEIN, 1999: 29).

${ }_{12}$ Algunos autores recurren, a este respecto, a la distinción entre «titularidad» $\mathrm{y}$ «ejercicio» para defender que la universalidad se predica de la titularidad pero no del ejercicio (vid., por ejemplo, CONTRERAS, 1994: 38). No me parece que el argumento así formulado sea correcto, como ha demostrado WESTEN en relación con la universalización de normas singulares (WESTEN, 1980: 81), aunque la conclusión que a fin de cuentas se trata de sostener es la misma que aquí se sostiene (CONTRERAS, 1994: 37-40).

13 Otras veces se habla de «absolutos» en sentido de no-limitados y no-excepcionables. Vid. RuIz Miguel, 1994: 656-659. Utilizo aquí una noción de «absolutos» más familiar en la dogmática continental que se refiere a los derechos (también llamados «de exclusión») que tienen eficacia contra todos.
} 
tisfacerlo, entonces ninguno de los derechos políticos clásicos sería absoluto y, en consecuencia, no serían derechos humanos. Los derechos políticos se predican de un sujeto frente al Estado del que el sujeto es ciudadano. El derecho de sufragio no se pretende que lo tenga todo ser humano respecto a los gobernantes de cualquier Estado, sino precisamente del Estado del que él forma parte y a cuyas decisiones normativas está habitualmente sometido. Cuando decimos que el derecho al sufragio o el derecho a un juicio justo es un derecho humano, decimos que cualquier persona tiene derecho moral al sufragio o, en su caso, a un juicio justo pero el obligado a satisfacer estos derechos depende nuevamente de la ocasión. El obligado —obligado moralmente y obligado por las declaraciones internacionales cuando han sido suscritas y, si todo va bien, obligado por las normas constitucionales internas- es el Estado al que una cierta persona pertenece como ciudadano, en el primer caso, y el Estado que procesa a una persona, aunque no sea ciudadano del estado, en el segundo caso. El Estado español no está obligado a proporcionar un juicio justo a los concentrados en el campamento de Guantánamo, sino que lo están precisamente los Estados Unidos de América y los internados en Guantánamo tienen ese derecho contra los Estados Unidos y no contra los demás.

Consecuentemente, el que los derechos económico-sociales se ostenten contra un estado, sociedad política o institución determinada no es una característica específica o peculiar de este tipo de derechos ${ }^{14}$.

\subsection{Sobre el pretendido carácter prima facie («los derechos económico-sociales no son derechos definitivos») ${ }^{15}$}

Si los derechos humanos tienen que ser derechos definitivos, en el sentido de que su configuración no depende de ulteriores precisiones institucionales sino que que-

\footnotetext{
${ }^{14}$ Sin embargo la importancia moral de los derechos humanos, en cuanto derechos morales básicos del individuo, tiene una cierta dimensión absoluta. Como señalaba Neil MACCORMICK «los padres tienen el deber de cuidar a sus hijos precisamente porque los niños tienen derecho a ser cuidados y alimentados... a falta de los padres... el derecho de los niños permanece y ha de recurrirse a otros medios para cumplimentarlo» (MACCORMICK, 1990: 135; vid. también en el mismo sentido HIERRO, 1982: 60). Esta exigencia de satisfacción subsidiaria no es privativa de los derechos-pretensión sino que es predicable también de derechos-libertad, derechos-potestad y derechos-inmunidad; precisamente porque todos los seres humanos tienen derecho a la libertad de expresión, al sufragio o a un juicio justo, a falta de la protección de su estado el derecho permanece y hemos de recurrir a otros medios para satisfacerlo, lo que explica y justifica la permanente reivindicación de una efectiva protección supranacional de los derechos humanos.

${ }_{15}$ También el calificativo de «prima facie» se utiliza, al menos, en dos sentidos diferentes como he señalado en otra ocasión (HIERRO, 2002, nota 84 en p. 67). Unas veces quiere decirse que no son derechos «absolutos» porque pueden entrar en conflicto y, si bien se consideran como «triunfos» a priori frente a otros valores o preferencias, ello no resuelve el problema cuando el conflicto es entre derechos humanos; en tal caso se requiere siempre una ponderación y un derecho (es decir, su satisfacción) puede tener que ceder total o parcialmente ante otro (GEWIRTH, 1984: 92; LAPORTA, 1987: 40-41). En este sentido la idea de derechos «prima facie» se opone a la de derechos «absolutos» en el sentido de no limitados. Otras veces quiere decirse que los derechos humanos requieren compromisos institucionales para convertirse en derechos «finales». Estos compromisos son en todo caso necesarios para convertir los derechos morales abstractos en derechos constitucionales concretos bajo cuya forma «final» los derechos son normalmente «complejos» de pretensiones, libertades, inmunidades y potestades (SCANLON, 1984: 139). Piénsese, por ejemplo, en la libertad positiva que es, en abstracto, una «potestad» y se manifiesta —entre otras cosas— en el derecho al sufragio cuya institucionalización implica la potestad de votar con fuerza decisoria, la libertad de elegir entre varias opciones, ciertas inmunidades (p. ej. el secreto del voto) y un sinfín de pretensiones frente al Estado (que convoque elecciones, realice censos,
} 
da definida por su mero enunciado, entonces prácticamente ninguno de los derechos individuales, civiles o políticos clásicos sería definitivo y, en consecuencia, no serían derechos humanos ${ }^{16}$. El derecho a la seguridad jurídica, por poner un solo ejemplo, no ha dejado de extender su configuración o contenido. Inicialmente se pretendía sólo que el monarca estuviese sometido a las leyes, que los juicios se celebrasen por autoridades judiciales preestablecidas y no por jueces ad hoc, o que no se embargasen los bienes inmuebles si el deudor disponía de bienes muebles; posteriormente se reclamó la publicidad formal de las leyes, la irretroactividad de las leyes penales o el derecho a la defensa letrada; todavía más tarde empezó a incluirse entre los contenidos de la seguridad jurídica un diseño estricto de la jerarquía de todas las disposiciones normativas, la motivación de las sentencias o la doble instancia en los juicios penales.

$\mathrm{El}$ argumento que ahora critico parece implicar que hay algunos derechos, los derechos individuales (y, quizá, los derechos políticos), cuya mera declaración surte, si se respeta, la configuración definitiva del derecho cuya realidad ya no se ve afectada por el ulterior desarrollo institucional y que, precisamente, un derecho es más claro, más intenso o más «real» en cuanto menos depende de su posterior configuración institucional. La respuesta a este argumento es doble. De un lado que, como ya he indicado, la configuración definitiva de un derecho siempre depende de ulteriores desarrollos institucionales y, de otro lado, que la claridad, realidad o intensidad del derecho en cuestión no depende de las posibilidades efectivas de satisfacerlo o protegerlo, aunque las requiera para obtener su configuración definitiva.

Si el sentido de afirmar que alguien tiene un derecho dependiese de las posibilidades actuales de satisfacer efectivamente su disfrute de tal derecho o, en su caso, de reparar efectivamente la violación de tal derecho, o si dependiese de esos mismos factores la importancia del derecho o su realidad (en el sentido, de resonancias realistas, en el que Carl WELLMAN distingue entre «real rights» y «paper rights»), entonces el derecho a la vida sería el derecho cuya afirmación tendría menos sentido, o el derecho de menor importancia o menos real (sería un «derecho de papel»).

La razón es sencilla. El derecho a la vida, considerado tradicionalmente como un derecho individual universal erga omnes, no es una libertad (en muchas concepciones morales y en muchos ordenamientos jurídicos el derecho a la vida se entiende compa-

\footnotetext{
publique listas, establezca colegios, etc.). Por otra parte los compromisos institucionales pueden configurar de muchas formas admisibles la periodicidad electoral, el sistema de demarcaciones, el carácter abierto o cerrado de las listas, etc. En este sentido la idea de derechos «prima facie» se opone a la de derechos «finales». Aquí utilizo esta segunda acepción.

${ }^{16}$ A veces esta pretendida característica se enuncia diciendo que los derechos económico-sociales no son estables, sino que tienen un carácter dinámico. Creo que los argumentos esgrimidos sirven igualmente para impugnar esta pretendida característica de los derechos económico-sociales. La propiedad privada, el derecho al sufragio, el derecho a un juicio justo, el derecho a la defensa letrada, el derecho a la intimidad... son derechos que se encuentran mucho más o mucho mejor satisfechos y protegidos en la legislación actual de los estados de Derecho de lo que lo estaban en el momento inicial de ser declarados, una vez que se han desarrollado, respectivamente, sistemas notariales y registrales públicos, sistemas electorales que incluyen censos exhaustivos y voto por correo, normas procesales que incluyen la doble instancia, turnos o servicios para la defensa de oficio o, en el último ejemplo, instituciones de protección de datos. Ello no significa que en los momentos iniciales de su declaración y positivación tales derechos fuesen inexistentes o meramente «manifesto sense». El carácter dinámico no es, desde luego, privativo de los derechos económico-sociales.
} 
tible con la prohibición del suicidio), ni es una inmunidad absoluta (al menos, en las concepciones morales y en los ordenamientos jurídicos que entienden compatible el derecho a la vida con la pena de muerte), ni es una potestad (aunque al hecho de vivir, unido a algunas ulteriores condiciones de competencia cognitiva, se le atribuyan potestades como las de contraer matrimonio o adquirir la propiedad), ni es una pretensión a recibir un bien que no se tiene o se ha perdido (la vida). El derecho a la vida es sólo el derecho a conservar la vida que ya se tiene y a no ser privado de ella por la acción de cualquier otro ser humano ni, allí donde también se entiende como inmunidad absoluta, por la acción del Estado. El contenido del derecho a la vida es sólo la pretensión de una serie de acciones normativas y fácticas por parte del Estado que prevengan las acciones homicidas. En una concepción más social de los derechos, el derecho a la vida incluye también la pretensión de una serie de acciones normativas y fácticas por parte del Estado que prevengan los hechos naturales que pueden privar de la vida, tales como las enfermedades mortales, las catástrofes naturales, los accidentes laborales o los accidentes de circulación. En ambos casos, el fundamento moral del derecho es asegurar el hecho de vivir (al que se atribuye un valor moral constitutivo) y el contenido del derecho es una pretensión de protección.

Pero —obvio es decirlo - si un asesino, una junta militar, una comida en mal estado, un huracán, un andamio sin protección o un conductor imprudente causan a alguien la muerte y violan, de este modo, su derecho a la vida, es sencillamente imposible restaurar al titular del derecho en el disfrute del mismo, como tampoco es posible disminuir el daño causado por la violación o compensarlo mediante una indemnización. No hay posibilidad alguna de recuperar la vida perdida, ni parte de ella, ni de recibir compensación alguna por su pérdida. En este aspecto el derecho a la vida, a diferencia de los derechos a la propiedad, a la integridad física, al honor, al sufragio, a la libertad o cualquier otro, es el derecho peor satisfecho y peor protegido. Nadie sostiene, sin embargo, que carezca de sentido afirmar el derecho a la vida o que el derecho a la vida sea menos importante, menos «real» o que sólo pueda declararse «manifesto sense».

El que el derecho a la vida admita tan escasa protección no significa, por otra parte, que no admita ninguna o que la poca que admite sea poco relevante. La acción normativa y fáctica del Estado para prevenir la violación del derecho puede tener una eficacia mayor o menor y, consecuentemente, la protección del derecho — en la medida sólo preventiva en que ella es posible- puede ser mayor o menor. Supongamos dos sistemas jurídicos cuyos respectivos textos constitucionales declaran en los mismos términos el derecho a la vida como derecho individual universal («Todos tienen derecho a la vida»); supongamos que sus códigos penales condenan con penas respectivamente idénticas de un lado el homicidio voluntario, de otro sus formas agravadas, de otro el homicidio por imprudencia, y de otro la denegación de auxilio con resultado de muerte; supongamos que sus leyes laborales contienen idénticas prescripciones sobre la seguridad laboral e idénticas sanciones contra los empresarios incumplidores, etc. Si el primero de esos países dispone de una extensa y eficaz policía, así como de una extensa y eficaz inspección de trabajo, de modo tal que el índice de delitos contra la vida y el índice de accidentes laborales mortales son muy bajos, mientras que en el segundo país la carencia de lo uno y de lo otro se traduce en índices muy altos, la conclusión es que el derecho a la vida está más protegido, y consecuentemente se disfruta más, en el pri- 
mero que en el segundo ${ }^{17}$. Los derechos, en cuanto situaciones normativas, tienen, como las normas, una dimensión de eficacia o vigencia que sólo la ceguera formalista puede desconocer o minusvalorar.

Consecuentemente, el que la configuración del derecho dependa de ulteriores precisiones institucionales y no de su mero enunciado no es una característica específica o peculiar de los derechos económico-sociales.

\subsection{Sobre el pretendido carácter costoso («los derechos económico-sociales no son derechos gratuitos ni baratos»)}

Posiblemente el argumento más tópico y que frecuentemente engloba o subsume a los anteriores es el que esgrime la escasez de recursos.

Si los derechos humanos tienen que ser derechos baratos para que su satisfacción y protección efectiva no dependa de la contingente asignación de recursos colectivos escasos, esta condición de gratuidad podría interpretarse de dos formas. De acuerdo con una primera interpretación la condición de gratuidad se interpretaría como que la satisfacción y la protección del derecho no tienen coste alguno para nadie. De acuerdo con la segunda interpretación la condición de gratuidad se interpretaría como que la satisfacción y la protección del derecho tienen algún coste pero éste es asumido por el propio titular del derecho.

La primera interpretación es implausible salvo asumiendo una teoría de los derechos como meras libertades o inmunidades verticales que se satisfacen con la mera abstención del Estado. Ningún liberal ha suscrito nunca semejante concepción de los derechos. Los liberales, desde LOCKE hasta ahora incluyendo los más radicales como HAYEK y NozICK, han sostenido sin empacho alguno que el Estado se justifica porque protege los derechos individuales, porque asume, al menos, el legítimo monopolio de la violencia conforme al cual queda abolida la defensa privada - que sólo es legítima en casos límite- y sustituida por la defensa pública de los derechos. De tal modo surge, como mínimo, un aparato estatal de defensa, un aparato estatal de policía y un aparato estatal de administración de justicia. Obvio es decir que todos ellos son caros y, con toda probabilidad, muy caros ${ }^{18}$. Naturalmente, lo mismo cabe decir de la implementación de derechos políticos, como el derecho al sufragio, cuya mera realización supone costosos sistemas públicos.

La segunda interpretación argumentaría que el coste de los derechos individuales se asume por su titular ${ }^{19}$. La protección de la propiedad mediante el sistema notarial, registral y judicial puede ser costeada por los propios titulares de los derechos de pro-

\footnotetext{
${ }^{17}$ «The amount the community chooses to expend decisively affects the extent to which the fundamental rights of Americans are protected and enforced» (HOLMES y SUNSTEIN, 1999: 31).

${ }^{18}$ El lugar clásico sobre la cuestión es el libro de Stephen HoLmes y Cass R. Sunstein, que vengo citando, The Cost of Rights. Why Liberty depends on taxes (1999). Vid. también RuIz Miguel, 1994: 659-660.

${ }^{19}$ HOLMES y SUNSTEIN subrayan que «the dependency of rights protection on private resources is well understood and has traditionally attracted greater attention that the dependency of rights protection on public resources» (HOLMES y SUNSTEIN, 1999: 21, donde se incluye una distinción entre costes presupuestarios, costes sociales y costes privados de los derechos).
} 
piedad mediante sistemas de aranceles y tasas, y esta ha sido ciertamente la forma más frecuente en los países liberales. Ello no tiene nada de extraño ya que, por definición, hablamos de la protección de la propiedad privada para aquellos seres humanos que se encuentran en la afortunada ocasión de ser propietarios. Pero ni siquiera la protección general que el sistema liberal implementó mediante el ejército, la policía y la justicia penal han dejado nunca de ser considerados bienes públicos en el estricto sentido económico y, por ello, costeados socialmente. Por otra parte asumir que el coste de los derechos dependa exclusivamente de la capacidad económica del titular es asumir una condición muy fuerte de desigualdad que es la que late, por supuesto, en el libertarismo de NOzICK. Es tanto como asumir que todos tienen derecho a la integridad física y derecho al honor pero que sólo se reparará la violación del derecho a la integridad física y del derecho al honor de quien tenga dinero para pagarla. Baste ahora señalar que, en la tradición liberal misma, se han instrumentado diferentes formas de asignar los costes de la protección según se trate del ejercicio de acciones civiles, del ejercicio de acciones penales (incluso distinguiendo delitos públicos y delitos privados), o de otras acciones institucionales como la protección registral de la propiedad inmueble o de la propiedad intelectual.

No hay, pues, nada cualitativamente distinto en implementar un sistema en el que los derechos económico-sociales (por ejemplo: el derecho a la educación o el derecho a la salud ${ }^{20}$ ) sean desarrollados como bienes públicos aunque sean costeados en ciertas ocasiones por quienes los disfrutan, mediante sistemas de aranceles o tasas, siempre y cuando puedan hacerlo ${ }^{21}$. La pretensión de que el derecho a la educación o el derecho a la salud tiene una estructura cualitativamente distinta, por razón de que implican costes, al derecho de sufragio o al derecho a la tutela judicial es una pretensión sin ningún fundamento ${ }^{22}$. Cuestión distinta es cómo distribuir ese coste. Por otra parte, la protec-

${ }^{20}$ Como señalan HOLMES y SunSTEIN, «investment in education closely parallels investment in the enforcement of property rights and the protection of owners from arson and acquisitive crime» (HOLMES y SUNSTEIN, 1999: 212).

${ }^{21}$ PECES BARBA suscita una cuestión interesante al señalar que, en los derechos económico-sociales, «se ha producido una gran confusión en el Estado social y se ha considerado como meta de estos derechos la generalización de los mismos a todos los hombres, con lo cual se ha desviado su objetivo y se han favorecido situaciones de injusticia. La llamada generalización de la protección de la salud o de la gratuidad de la enseñanza, han desvirtuado la finalidad de esos derechos al acoger a quienes tienen medios para satisfacer esas necesidades, junto a los que no podían hacerlo por sí mismos» (PECES BARBA, 1999: 65-66). Frente a ello PeCES BARBA propone, respecto a estos derechos, un criterio de igualdad-como-diferenciación que sirva para alcanzar la igualdad-como-equiparación y ello le conduce a concluir que en los derechos individuales, civiles y políticos «los destinatarios son todas las personas» mientras que en los derechos económico-sociales los destinatarios son «sólo los afectados por las carencias» (ibidem, p. 66). En mi opinión es claro que PECES BARBA está argumentando sobre la distribución de los costes y sobre en qué ocasiones el Estado ha de resultar el obligado directo a satisfacer el derecho y en cuáles sólo estaría obligado a garantizar su protección. PECES BARBA coincidiría conmigo en que cualquier niño, por rica que sea su familia, tiene derecho a la educación o en que cualquier persona, por muy adinerada que sea, tiene derecho a la protección de su salud. Otra cosa es cómo distribuir el coste de lo uno y de lo otro.

${ }_{22} \mathrm{El}$ argumento en contra —esto es: que los derechos económico-sociales tienen una estructura cualitativamente distinta a los derechos individuales, civiles y políticos- es muy común en la doctrina. Por ejemplo, Francisco J. CONTRERAS lo sostiene con abundante apoyo bibliográfico aunque, para «conservar su viabilidad», excluye de la clase de los derechos económico-sociales el derecho a la libertad sindical y el derecho de huelga. El argumento principal estriba en que las libertades sólo exigen una acción del Estado de carácter adjetivo (CONTRERAS, 1994: 31) mientras que para los derechos económico-sociales «la prestación estatal representa verdaderamente la sustancia, el núcleo, el contenido esencial del derecho». En tal caso, estos autores deberían concluir también que el derecho a la seguridad jurídica o el derecho al sufragio son derechos económico-sociales. 
ción de los derechos cuando han sido violados implica, en todo caso, costes tanto se trate del derecho a la vida o del derecho al honor como del derecho a la salud o del derecho al medio ambiente. Cuestión distinta es, nuevamente, cómo se distribuyan esos costes.

Que el sistema educativo publico o el sistema sanitario público sea más costoso que el sistema policial o el sistema electoral, aparte de ser empíricamente discutible, sólo arrojaría una diferencia cuantitativa que no puede traducirse en una pretendida diferencia ontológica entre el derecho a la educación o el derecho a la salud, de un lado, y el derecho a la propiedad privada o el derecho al sufragio, del otro.

\subsection{Sobre el pretendido carácter programático («los derechos económico-sociales no son derechos justiciables»)}

De las anteriores pretendidas diferencias suele derivarse como corolario que los derechos individuales, civiles y políticos son justiciables mientras que los derechos económico-sociales no son justiciables ${ }^{23}$.

De acuerdo con lo que ya he indicado deberíamos admitir que el derecho a la vida, para aquel titular que es privado de él, no es un derecho justiciable. De ello no se deriva que no sea un derecho y que no deba ser, hasta donde es preventivamente posible, protegido. Que un derecho admita una protección judicial directa perfecta o reparadora (digamos, la reivindicación o restauración del titular en el disfrute del derecho, como el derecho de propiedad) o una protección judicial directa imperfecta o compensadora (digamos, la indemnización por la violación del derecho, como el derecho a la integridad física) o una protección judicial indirecta generalmente preventiva (digamos, una sanción al que viola el derecho, como el derecho a la vida) no se deriva que uno sea un derecho más importante o más real que otro, sino sencillamente que uno es más fácil de satisfacer o de proteger que el otro.

Que existan derechos cuya satisfacción no puede obtenerse de forma directa y perfecta mediante una decisión judicial no resta nada a la fuerza del argumento moral que exige que ese derecho sea satisfecho, aunque su satisfacción requiera la actividad legislativa y «contar para su realización con una determinada estructura y organización en el campo económico y social» (CASCAJO, 1988: 30) ni impide que el ordenamiento jurídico prevea que, cuando el derecho no puede ser satisfecho de esa forma, el juez dicte una decisión compensadora o sancionadora. Que el juez, en un Estado de Derecho, sólo podrá dictar tal tipo de resoluciones si las leyes le autorizan a hacerlo es una trivialidad cuando se esgrime como argumento diferenciador de los derechos económico-sociales. Mientras la regla de reconocimiento entonces vigente sólo atribuyó a la parte de-

${ }^{23}$ Todo el largo capítulo 3 de ABramovich y CourTis (2002: 117-254) analiza la justiciabilidad. Parten allí de que los obstáculos a la exigibilidad de los derechos sociales ante los tribunales son, pretendidamente, cuatro: la determinación de la conducta debida (que quedaría incluido en el argumento que he discutido sub. 2.3); la autorrestricción judicial en cuestiones políticas y técnicas; la ausencia de mecanismos procesales adecuados; y la escasa tradición del control judicial específico de este tipo de derechos. Ellos ofrecen un interesante análisis de las estrategias judiciales desarrolladas por diferentes tribunales para superar estos obstáculos. Vid. también los trabajos, más convencionales, de M. SCHEININ, 2001 y S. LiEBENBERG, 2001. 
clarativa de las constituciones un valor programático y no la eficacia jurídica directa - como ocurrió durante largas décadas en los países europeos- los jueces no podían proteger la libertad de prensa sino en los términos previstos por la legislación de prensa que, con frecuencia, admitían la censura gubernativa. Ello sólo significa que la libertad de prensa estaba legalmente muy mal protegida, no que no constituyera un derecho moral y, allá donde estaba constitucionalmente declarado, un derecho constitucional mal protegido. El que una constitución, o la legislación que la desarrolla, no proteja eficazmente (incluso mediante la autorización de decisiones judiciales reparadoras, compensadoras o sancionadoras) el derecho a la educación o el derecho a la salud sólo significa que el derecho a la educación o el derecho a la salud están legalmente muy mal protegidos en tales casos.

Me parece que arrastramos un insostenible prejuicio cuando, con tanta frecuencia, se argumenta sobre las dificultades de protección judicial de los derechos económico-sociales frente a una supuesta facilidad en la protección judicial de los derechos individuales. Creo que hay que subrayar, nuevamente, que el error se encuentra en el pretendido punto de partida, esto es: en la supuesta facilidad y eficacia inmediata de la protección jurisdiccional de los derechos individuales. Este punto de partida, que suele darse por evidente, parece insinuar que el juez no ha requerido la intervención del legislador para proteger los derechos individuales. Es difícil, si no imposible, concebir cómo podría llevarse a cabo una fácil e inmediata protección del derecho de propiedad, del derecho de sufragio, del derecho a la vida, de la libertad de expresión o del derecho al honor sin la mediación de la legislación civil, la legislación electoral, la legislación penal y la legislación procesal. La principal diferencia entre los derechos individuales y los derechos sociales no estriba, a efectos de su justiciabilidad, en que los primeros no requieran la mediación del legislador y los segundos sí, sino en que la mediación legislativa para configurar los derechos individuales ya estaba, en gran medida, satisfecha en la tradición jurídica occidental (vida, propiedad, libertad de comercio, honor, etc.) y fue corregida y completada — principalmente mediante su generalización formal y su sistematización- en el período de las revoluciones burguesas mientras que tal mediación legislativa para configurar los derechos sociales se inicia, básica y tímidamente, en el siglo XX y está todavía haciéndose.

\section{EXCURSO SOBRE LOS DERECHOS QUE NO SON DERECHOS}

El constituyente y el legislador, sea cual sea el mágico poder que les atribuimos, pueden hacer mucho, casi todo, e incluso a veces decir tonterías. En España es proverbial la ingenua pasión humanista que inspiró al constituyente de 1812 que, a pesar de las protestas del diputado Villanueva (FERNÁNDEZ AlMAGRO, 1928: 140), acabó por incluir en su artículo 6 la obligación de los españoles de «ser justos y benéficos». No menos ingenuos fueron los pueblos de las colonias americanas que declararon como un derecho el derecho a la felicidad pero, como dijo RICHTIE:

The right, not merely of pursuing but of obtaining happiness, which is named as one of the natural rights of man in most American State Constitutions, may seem, in this world of ours, to be a very large order in the bank of Providence (RITCHIE, 1924: 272). 
Los derechos se invocan, a veces, como meras aspiraciones o pretensiones ideales sin que sea posible definir quién es el obligado a satisfacerlos ni cuál la forma de protegerlos. Joel FEINBERG ha expuesto con claridad el uso retórico del concepto «derechos humanos» en lo que denomina un «manifesto sense» cuando «un derecho no necesita ser correlativo con el deber de otro» (FEINBERG, 1980: 153). FEINBERG mira con simpatía este uso retórico aunque prefiere un concepto más estricto conforme al cual «tener un derecho es tener una pretensión contra alguien cuyo reconocimiento como válida viene requerido por algún conjunto de reglas efectivas o de principios morales» (ibidem, p. 155).

Esta opción por un concepto normativamente estricto de «derechos» tiene dos implicaciones: que todo derecho es correlativo de uno o más deberes de otro u otros y que tales deberes pueden ser satisfechos pues nadie está obligado a lo que no puede hacer. Los deberes correlativos pueden ser deberes positivos (como obligaciones o sujeciones) o deberes negativos (como abstenciones o incompetencias) y pueden ser deberes generales (o de todos) o deberes especiales (o de algunos) pero, en cualquier caso, si no es posible establecer sobre nadie el deber que satisface el derecho carece de sentido afirmar que el derecho existe pues no pasa de ser un «cheque contra la Providencia». En términos jurídicos esto significa que si un orden legal dado declara un cierto derecho sin establecer los deberes jurídicos correspondientes a su satisfacción, simplemente el derecho no existe como derecho subjetivo positivo en ese ordenamiento jurídico o, lo que es igual, es un «derecho de papel». Esto significa igualmente que si, en términos morales, no podemos razonablemente fundamentar el deber de nadie para satisfacer un derecho, entonces no podemos razonablemente afirmar que tal derecho existe. PÉREZ LuÑo ha considerado que esta restricción que ya propuse hace años (HIERRO, 1982: 60) supone privar a los derechos de «su dimensión emancipatoria y su propio contenido axiológico» porque identifica a los derechos «con los contenidos empíricos del derecho positivo de cada sistema político» (PÉREZ LUÑO, 2003: 175-176) ${ }^{24}$. La restricción, sin embargo, tiene un mero carácter conceptual y pretende configurar un concepto claro y riguroso - aunque no voluntarista- de «derechos». No supone, desde luego, ninguna reducción al derecho positivo pues, en términos morales, uno puede y debe someter a crítica «las condiciones de posibilidad para la realización de los derechos» (ibidem $)^{25}$. Sí supone, sin embargo, que enunciar el «derecho a la felicidad», sea cual sea su carácter emancipatorio, no tiene sentido alguno, como ya hemos visto que señaló RITCHIE; supone también que «los derechos o, por así decirlo, su contenido se expanden al mismo ritmo al que se expande la riqueza material y cultural de una sociedad» (HIERRO, 2002: 51).

\section{LOS DERECHOS ECONÓMICO-SOCIALES EN LA DOGMÁTICA DE ROBERT ALEXY}

De acuerdo con el propósito de este trabajo trataré ahora de comparar la reconstrucción teórica de los derechos sociales que ALEXY propone con las presuntas diferen-

${ }^{24}$ Francisco J. CONTRERAS va más lejos afirmando, en relación con mi trabajo de 1982, que la «reserva económica de lo posible» supone «asestar una puñalada en la espalda a la utopía de los derechos humanos, el gran ideal de los tiempos modernos» (CONTRERAS, 1994: 114). Aunque esta gruesa afirmación, y las que la siguen, tienen mucho de retórico, sería fácil responderle que a algunos nos preocupan los derechos humanos que pueden estar en alguna parte y que, por ello, no son u-tópicos.

${ }^{25}$ Eso he tratado de hacer, por ejemplo, en relación con la eficiencia productiva en HIERRO, 2002b. 
cias entre derechos individuales y derechos sociales que acabo de comentar. Conviene comenzar por recordar esquemáticamente el sistema de los derechos fundamentales que AlEXY ofrece y que es el siguiente:

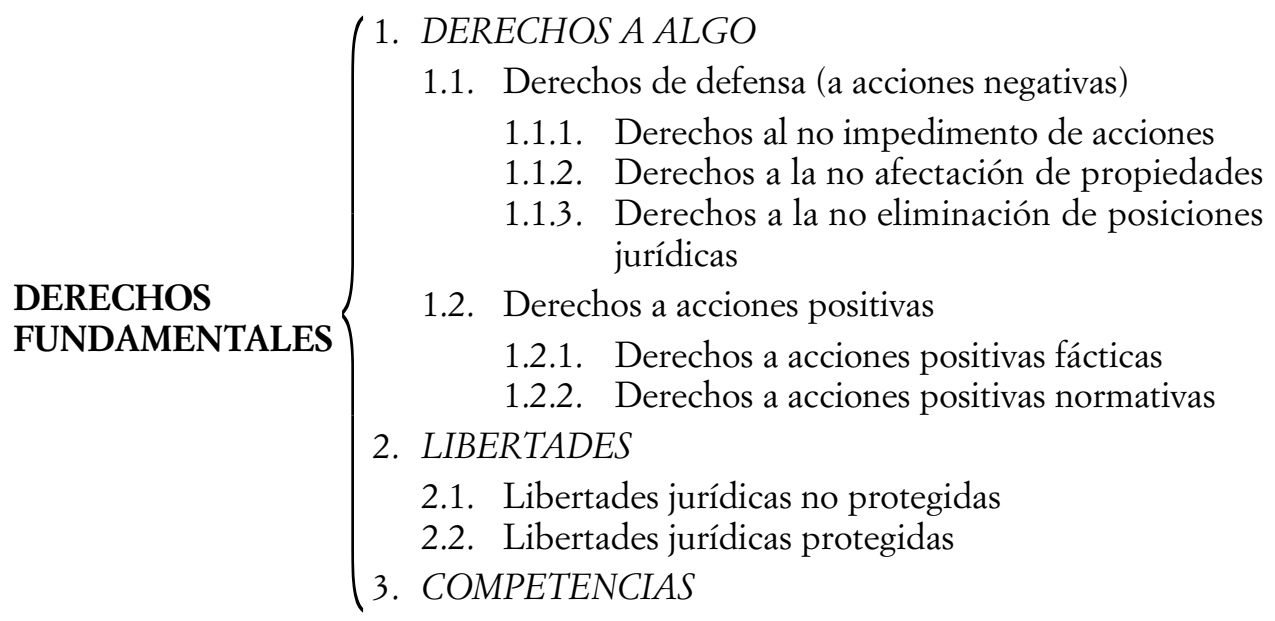

Afortunadamente ALEXY prescinde de las tradicionales distinciones entre derechos individuales y derechos sociales para ofrecer una clasificación de los derechos fundamentales basada en su estructura deóntica y no en los avatares de su aparición histórica. Los derechos económico-sociales se sitúan, en este esquema, como derechos a acciones positivas del Estado o prestaciones en sentido amplio (1.2). Estos derechos a prestaciones en sentido amplio abarcan diversas modalidades, «desde la protección del ciudadano frente a otros ciudadanos a través de normas del Derecho penal, pasando por el dictado de normas de organización y procedimiento, hasta prestaciones en dinero y en bienes» (ALEXY, 1993: 427) por lo que AlEXY —admitiendo que hace un uso de la expresión «prestaciones» más amplio del que es habitual (ibidem, p. 428)— propone subdistinguir tres grupos de derechos a prestaciones en sentido amplio: 1) los derechos a protección, 2) los derechos a organización y procedimiento y 3) los derechos a prestaciones en sentido estricto (ibidem, p. 430), advirtiendo que los «llamados derechos fundamentales sociales, es decir, por ejemplo, los derechos a la asistencia social, al trabajo, la vivienda y la educación... constituyen un sector importante de aquello que puede ser llamado "derecho a prestaciones", pero no agotan su ámbito» (ibidem, p. 420).

\subsection{Los derechos a protección}

Según ALEXY los derechos a protección son los derechos que alguien tiene frente al Estado «para que éste le proteja de las intervenciones de terceros» (ibidem, p. 435). Se trata de la protección de muy diferentes cosas, tales como la vida y la salud, la libertad, la familia o la propiedad, y lo que tienen en común los derechos a protección es que se trata de derechos constitucionales frente al Estado para que éste haga algo, bien normativamente bien fácticamente (ibidem, p. 436). Cuando ALEXY opta por afirmar 
que existen propiamente derechos a protección como derechos subjetivos fundamentales específicos que son derechos distintos (y que no se trata, pues, de meras normas objetivas que establezcan un deber del Estado) concluye que estos derechos a protección, a diferencia de los meros derechos de defensa (que sólo requieren acciones negativas del Estado), «comparten una serie de problemas con los derechos sociales fundamentales, con los derechos a prestaciones en sentido estricto... La comunidad de problemas pone, además, de manifiesto que el foso que separa los derechos de la tradición liberal de los derechos propios del Estado social no es tan profundo como podría pensarse a primera vista» (ibidem, p. 441).

Hasta este punto la propuesta de ALEXY me parece impecable. El problema comienza, en mi opinión, cuando ALEXY trata de diferenciar entre los derechos a protección y los derechos de defensa. La diferencia nuclear entre los meros derechos de defensa y los derechos a protección estriba en que respecto a los primeros el Estado sólo tiene «el deber de omitir intervenciones» mientras que respecto a los segundos tiene «el deber de encargarse de que terceros omitan intervenciones». ALEXY discute ampliamente las objeciones a la distinción entre derechos de defensa y derechos a protección. La discusión, sin embargo, no resulta en mi opinión nada concluyente. El problema no estriba — creo yo- en si cabe establecer una distinción dogmática entre los derechos de defensa y los derechos a protección sino en si los derechos a protección no son una categoría redundante respecto al derecho a aquella cosa que se protege, sea la vida, la libertad, la familia, la propiedad, etc. Si aceptamos las categorías de ALEXY resulta que alguien tiene un derecho a la libertad de expresión (al que llamaremos DLE ${ }^{1}$ ) y un derecho de defensa a la libertad de expresión frente a la acción del Estado (al que llamaremos $\mathrm{DLE}^{2}$ ) y un derecho a la protección de la libertad de expresión frente al Estado para que evite la violación del derecho por la intervención de particulares (al que llamaremos $\mathrm{DLE}^{3}$ ). La libertad de expresión, o el derecho a la vida, o el derecho a la propiedad, etc., se desdoblan de este modo en uno o varios derechos de defensa y uno o varios derechos de protección dando lugar a una multiplicación innecesaria de entidades.

Bastaría decir, por el contrario, que si alguien tiene un derecho erga omnes a la libertad de expresión (éste es el ius) entonces la satisfacción del derecho requiere garantizar normativamente que ni las autoridades del Estado ni los particulares pueden intervenir impidiendo el ejercicio o disfrute de ese derecho, y que la protección del derecho exige medidas normativas y/o fácticas tendentes a evitar tales intervenciones (este es el remedium). Naturalmente, el derecho está mejor satisfecho o más protegido en la medida en que el remedio es más eficaz. El remedio puede incluir medidas normativas y fácticas muy distintas (acciones preventivas, medidas sancionadoras, medidas resarcitorias, etc.) pero el remedio no constituye un derecho distinto o un conjunto distinto de derechos sino un elemento de la configuración institucional del derecho ${ }^{26}$.

El segundo problema de la disociación entre derechos de defensa y derechos a protección estriba en que, de acuerdo con la propia dogmática de ALEXY, la protección de

${ }^{26}$ Nada tengo que objetar, por supuesto, a la distinción que ALEXY introduce en esta discusión entre los derechos cuya satisfacción requiere deberes negativos generales, por lo que sólo la omisión de todas las acciones de violación satisface el derecho, y los derechos cuya satisfacción requiere deberes positivos (especiales o generales), por lo que la realización de una sola acción adecuada ya satisface el derecho (vid., ibidem, p. 447). La cuestión es, como enseguida discuto, si todo derecho requiere del Estado alguna acción de protección, esto es, alguna acción positiva. 
cualquier derecho requiere un específico derecho a protección. ALEXY admite, por ejemplo, que el derecho al honor personal forma parte del derecho general abstracto a la personalidad (ibidem, p. 356). Pues bien, si reconocemos (por ejemplo, en una constitución) el derecho al honor personal parece obvio que, para superar la mera retórica declarativa, hemos de reconocer que el derecho al honor personal tiene algún tipo de protección (remedium) ya sea mediante el derecho a la rectificación, la sanción penal de las injurias y calumnias, la actividad de una agencia de protección de datos, o cualesquiera otros instrumentos normativos y fácticos. No se me ocurre ningún derecho de tipo alguno que no requiera una u otras formas de protección y, en este sentido, todos los derechos darían lugar a derechos a protección y, consecuentemente, no existirían derechos-sin-derecho-a-protección ni derechos-a-protección-sin-derecho-que-proteger, lo que pone en duda la autonomía de la categoría «derechos a protección».

\subsection{Los derechos a organización y procedimiento}

Para explicar la existencia de los derechos a organización y procedimiento —que, como ya vimos, son el segundo tipo de derechos a prestaciones en sentido amplioALEXY cita muy oportunamente una sentencia del Tribunal Constitucional alemán para señalar que «de acuerdo con la concepción constitucional... una protección jurídica efectiva - que asegure la existencia de la propiedad - es un elemento esencial del derecho fundamental mismo» e incluso que, como consecuencia de la doctrina constitucional, «a todo derecho fundamental material le están adscriptos derechos procedimentales» (ibidem, p. 460). Coherentemente con su construcción dogmática ALEXY considera que los derechos a organización y procedimiento son esencialmente competencias que incluyen 1) competencias de Derecho privado, 2) procedimientos judiciales y administrativos, 3) organización en sentido estricto y 4) formación de la voluntad estatal (ibidem, p. 468).

$\mathrm{Al}$ analizar las competencias de Derecho privado ALEXY constata con claridad meridiana que el matrimonio o la propiedad son situaciones que requieren la concurrencia de normas constitutivas por lo que el derecho a la propiedad o el derecho a contraer matrimonio es lo mismo que el derecho a normas que establezcan la propiedad o a normas que instituyan el matrimonio. Prescindiendo ahora de que ello implica que quien afirme que existe un derecho moral a la propiedad o al matrimonio ha de configurar de qué tipo de propiedad o de matrimonio está hablando, lo interesante es que, en este punto, ALEXY propone la siguiente generalización:

No existen, primero, garantías institucionales objetivas que, a través del aseguramiento de un conjunto básico de normas sirvan para el aseguramiento de derechos fundamentales y, segundo, derechos fundamentales como derechos subjetivos que de esta manera son asegurados, sino que existe un derecho subjetivo a la vigencia de normas de derecho privado que son necesarias para que sea posible aquello que garantiza el derecho fundamental (ibidem, p. 471).

Aquí, si yo entiendo bien, ALEXY disuelve la dualidad entre un presunto derecho a la organización de la propiedad y un derecho de propiedad. El derecho de propiedad es cabalmente el derecho a la organización de la propiedad. Según él, el derecho de propiedad es el derecho frente al Estado a que tengan validez las normas que instituyen la 
propiedad y el entenderlo así sólo «agrega la subjetivización al mero aseguramiento objetivo» (ibidem), lo que «es indispensable si los derechos fundamentales son tomados en serio como derechos individuales» (ibidem). No tengo nada que objetar pues mi única objeción, como antes he indicado, estriba en que idéntica construcción teórica me parece aplicable —o generalizable - a cualquier tipo de derecho. Naturalmente soy consciente de que la vida, la integridad física o incluso el honor, a diferencia de la propiedad privada o del matrimonio, no requieren normas constitutivas pero no veo nada que impida afirmar que el derecho a la vida, a la integridad física o al honor son derechos subjetivos a la vigencia de normas que son necesarias para que sea posible aquello que garantiza el derecho fundamental.

Desde luego que ALEXY tiene razón cuando afirma que «los derechos a procedimiento en sentido estricto sirven, en primer lugar, para la protección de posiciones jurídicas existentes frente al Estado y frente a terceros» (ibidem, p. 474) por lo que pueden reducirse a derechos a protección. El análisis de los dos restantes grupos (los derechos a organización en sentido estricto, como por ejemplo el derecho a una organización pluralista e independiente de la radiodifusión, y los derechos a la formación de la voluntad estatal) suscitan cuestiones similares a los dos anteriores que ALEXY resuelve en términos paralelos: se trata de derechos subjetivos a que el Estado dicte ciertas normas mediante las que se configura y satisface el derecho individual a una determinada forma de radiodifusión o el derecho individual a ejercer la competencia de votar.

Mi opinión es que la afirmación de ALEXY antes citada (ibidem, p. 471) es generalizable a cualquier derecho, incluso a los llamados derechos de defensa. Podríamos decir que, en cualquier caso, no existen, primero, garantías institucionales objetivas y, segundo, derechos fundamentales de esta manera asegurados, sino que existe un derecho subjetivo a la vigencia de normas de derecho público y/o de derecho privado que son necesarias para que sea posible aquello que garantiza el derecho fundamental. Consecuentemente, todos los derechos, incluso los derechos de defensa, requieren para estar garantizados acciones normativas y/o fácticas por parte del Estado y, por ello, todos los derechos, incluso los derechos de defensa, se convierten en derechos a protección y, puesto que los derechos a protección se convierten en derechos a organización y procedimiento, quiere decirse que todos los derechos incluso los derechos de defensa se convierten en derechos a organización y procedimiento y son derechos a prestaciones en sentido amplio.

Por otra parte, ni los derechos a protección ni los derechos a organización y procedimiento ofrecen, en ALEXY, una configuración definitiva en el sentido de que su mero enunciado implique una determinada forma de estos derechos los cuales revisten, por ello, un carácter de derechos prima facie que pueden ser satisfechos y protegidos mediante acciones normativas diversas del legislador. Interesa subrayarlo, de forma preliminar, para comprobar enseguida que son en este aspecto perfectamente similares a los derechos a prestaciones en sentido estricto.

\subsection{Los derechos a prestaciones en sentido estricto}

De acuerdo con ALEXY los derechos a prestaciones en sentido estricto «son derechos del individuo frente al Estado a algo que — si el individuo poseyera medios finan- 
cieros suficientes y si encontrase en el mercado una oferta suficiente- podría obtenerlo también de particulares» (ibidem, p. 482).

AleXY distingue, en relación con este tipo de derechos tres posibilidades teóricoestructurales según las normas que los reconozcan: que se trate de derechos subjetivos o sólo de normas objetivas, que se trate de normas vinculantes o de normas no vinculantes, y que se trate de derechos/deberes definitivos o prima facie ${ }^{27}$. AlEXY da por supuesto que esa diversidad de posibilidades tiene como consecuencia que «en el problema de los derechos fundamentales sociales no puede tratarse de una cuestión de todo o nada» (ibidem, p. 486).

ALEXY sólo discute dos objeciones a los derechos sociales a las que denomina formal y material (ibidem, pp. 489-490). La objeción formal, según ALEXY, estriba en el dilema que se produce entre vinculación y competencia: «si los derechos fundamentales sociales son vinculantes, conducen a un desplazamiento de la política social desde la competencia del parlamento a la del Tribunal Constitucional; si no son vinculantes, conducen a una violación de la cláusula de vinculación del artículo 1 párrafo $3 \mathrm{LF}$ » (ibidem, p. 490). En realidad la objeción formal incluye, si uno lee atentamente, tres de las aporías que antes he manejado: la de la no-definitividad, la de la no-gratuidad y la de la no-justiciabilidad (ibidem, pp. 490-491). La objeción material, por su parte, pretende que los derechos sociales son inconciliables con ciertos derechos de libertad, con otros derechos sociales y con bienes colectivos.

Para responder a estas objeciones ALEXY invoca la «idea rectora» que había esbozado al principio del capítulo IX (ibidem, p. 432) conforme a la cual «los derechos fundamentales son posiciones tan importantes que su otorgamiento o no otorgamiento no puede quedar en manos de la mayoría parlamentaria». ALEXY propone, en consecuencia, una ponderación de los principios en juego: el principio de libertad fáctica que sería el principal fundamento de los derechos sociales (ibidem, pp. 486-489), el principio democrático de decisión, el principio de la división de poderes y el principio de la libertad jurídica de otros así como los otros derechos sociales y los bienes colectivos. $\mathrm{Si}$ una prestación es requerida por el principio de libertad fáctica y los principios opuestos son afectados «en una medida relativamente reducida» (ibidem, p. 495), entonces cabe admitir que está garantizado por la Constitución y, según AlEXY, tales condiciones se satisfacen «en el caso de los derechos fundamentales sociales mínimos, es decir, por ejemplo, a un mínimo vital, a una vivienda simple, a la educación escolar, a la formación profesional y a un nivel estándar mínimo de asistencia médica» (ibidem).

\subsection{Igualdad formal e igualdad material: la ponderación y la hipótesis del mínimo}

Si uno trata de escudriñar mediante qué ponderación el profesor ALEXY llega a esta tímida conclusión tiene que volver hacia atrás y repasar sus consideraciones sobre el derecho a la igualdad. Para ALEXY, si el mandato contenido en el artículo 3, párrafo 1, de la Ley Fundamental de Bonn («todas las personas son iguales ante la ley») se interpretara como la mera exigencia de «una práctica universalista de decisión» (ibidem,

27 Vid. cuadro en AleXY, 1993: 484. 
p. 386) podría ser satisfecho siempre que las normas se formularan bajo la forma de normas universales ${ }^{28}$. La consecuencia es, en palabras de ALEXY, que «sólo si la fórmula "Hay que tratar igual a lo igual y desigual a lo desigual" no es interpretada como exigencia dirigida a la forma lógica de las normas sino como exigencia a su contenido, es decir, no en el sentido de un mandato de igualdad formal sino material» se puede concluir una concreta vinculación del legislador a tal mandato constitucional (ibidem, p. 386). La conclusión que ALEXY propone es que la norma de igualdad de tratamiento y desigualdad de tratamiento opera de forma asimétrica ya que obliga prima facie a un tratamiento igual salvo que existan razones que justifiquen un tratamiento desigual por lo que a favor de la igualdad de iure existe una carga de argumentación que no existe a favor de la igualdad de hecho (ibidem, p. 412).

Hasta aquí no hay nada que oponer a la construcción de ALEXY. Los problemas comienzan cuando ALEXY afirma, un tanto apodícticamente, que «no puede haber ninguna duda de que el principio de la igualdad de iure no puede ser sacrificado en aras de la igualdad de hecho» (ibidem, p. 406). Antes de continuar la discusión he de advertir que ALEXY, en este punto, se pone la venda antes de recibir la herida, advirtiendo — citando a DREIER - que «la interpretación de la máxima de la igualdad que uno elija depende de la filosofía del derecho y del Estado que uno posea» (ibidem, p. 407).

Es claro que la filosofía del Derecho y del Estado que suscribe ALEXY parece asumir sin mucha discusión tres axiomas notoriamente conservadores. El primero es que la igualdad de iure no puede ser sacrificada en aras de la igualdad de hecho, axioma que no se deriva de su propio argumento de que existe una carga de la argumentación a favor de la igualdad formal, ya que si esta presunción es sólo prima facie - lo que el mismo ALEXY parece admitir- entonces cabe argumentar en favor de sacrificios de la igualdad formal en aras de la igualdad material. El segundo es que el fundamento principal de los derechos sociales o derechos a prestaciones en sentido estricto sea el principio de libertad fáctica y no el principio de igualdad o, dicho de otro modo, de igualdad de oportunidades para la libertad fáctica. El tercero es que los derechos a prestaciones en sentido estricto son derechos a bienes que uno podría adquirir en el mercado si tuviese recursos suficientes. En este tercer axioma se incluye una cierta petición de principio pues se da por supuesto, sin argumento alguno, que un sistema educativo público o un sistema sanitario público sólo se justifican como remedio subsidiario para solucionar carencias del lado de la oferta o del lado de la demanda mientras que es perfectamente argumentable que se justifican para satisfacer derechos fundamentales y que es la iniciativa privada la que tiene un mero papel subsidiario en la creación de estos servicios, papel que puede justificarse en base al principio de libertad de empresa y, en el caso de la educación, al principio de libertad ideológica.

A partir de estos tres axiomas Alexy construye su teoría del mínimo. Probablemente hay muchas otras razones por las que cabe concluir, coincidiendo con AlEXY, que la capacidad del Tribunal Constitucional para controlar el desarrollo legislativo de los derechos sociales sólo alcanza a controlar si la legislación se sitúa por debajo de un mínimo constitucionalmente inadmisible. Pero sería importante tener en cuenta que la

${ }^{28}$ En mi opinión, ALEXY tiene, en este punto, toda la razón como he tratado de demostrar en un reciente trabajo (HIERRO, 2003). 
capacidad de un Tribunal Constitucional para controlar si la legislación implementa adecuadamente los derechos a protección, organización y procedimiento tampoco alcanza más allá de un mínimo constitucionalmente inadmisible y, puesto que todos los derechos se traducen en derechos a protección, organización y procedimiento, ello significa que el control de constitucionalidad de las acciones normativas y fácticas del Estado para satisfacer y proteger los derechos fundamentales es siempre necesariamente un control de mínimos.

ALEXY termina sosteniendo, de un lado, que vinculación jurídica es igual a control judicial y, de otro lado, que los principios contienen exigencias normativas al legislador que van más allá de los límites de lo definitivamente debido, es decir, de lo jurídicamente vinculante (ibidem, pp. 500 y 501 y ALEXY, 2004: p. 101). Ambas conclusiones me parecen perfectamente correctas pero en modo alguno aplicables exclusivamente a los derechos a prestaciones en sentido estricto, esto es, a los derechos económico-sociales. Respecto a estos, como respecto a cualquier otro derecho fundamental, el control constitucional es un control restringido a lo jurídicamente vinculante, pero respecto a estos, como respecto a cualquier otro derecho fundamental, el legislador está sometido a un mandato de optimización ${ }^{29}$.

\section{EPÍLOGO SOBRE EL «EPÍLOGO» Y CONCLUSIONES}

El «Epílogo» que Robert ALEXY escribió para la edición inglesa de su teoría (ALEXY, 2004) desarrolla, principalmente, una discusión sobre el alcance de la optimización y el papel de la ponderación con el propósito de responder a dos críticas: la primera es que la concepción de los derechos fundamentales como mandatos de optimización les quita su característica fuerza deontológica y los deja en manos del legislador (objeción de HABERMAS); la segunda, que una interpretación expansiva de esta misma concepción priva de toda autonomía al legislador y da paso al estado jurisdiccional (objeción de BÖCKENFÖRDE) (ALEXY, 2004: pp. 14-20, donde denomina a estos argumentos como, respectivamente, «demasiado poco» $\mathrm{y}$ «demasiado»).

Aparentemente no hay nada en este «Epílogo» que modifique explícitamente la concepción teórica de ALEXY sobre los derechos económico-sociales. Me parece, sin embargo, que sí cabe observar alguna rectificación implícita y ella es la poca relevancia que ahora se concede, en el contexto de aquella doble discusión, a la distinción entre derechos a acciones negativas y derechos a acciones positivas. Ello no obstante, la contribución de ALEXY al Seminario celebrado en Madrid en noviembre de 2004 (ALEXY, 2005) vuelve a centrarse en los derechos a acciones positivas. La justificación de ALEXY para hacerlo así

${ }^{29}$ Esto es algo generalmente asumido, y reclamado, por los defensores de los derechos económico-sociales. Las conclusiones de Sandra LIEBENBERG son un buen ejemplo de ello y resultan, a este respecto, tan certeras como triviales. La mejor protección de los derechos económico-sociales — sostiene- requiere varios mecanismos: $a$ ) la inclusión de estos derechos en la legislación y, preferiblemente, en la norma suprema, $b$ ) políticas y legislación que les concedan efectos concretos («comprehensive policies and legislation that give concrete effect to the rights»); c) remedios accesibles y efectivos de carácter judicial y administrativo contra su violación y $d$ ) instituciones nacionales apropiadas revestidas de poder para controlar e investigar su realización (LIEBENBERG, 2001: 84). Lo único que cabe añadir, por última vez, es que exactamente lo mismo es lo que requiere la mejor protección de los derechos individuales, civiles y políticos. 
parece ser meramente argumental («The question of whether or not the expansion of constitutional rights reduces the competence of parliament to an unacceptable degree, is therefore a touchstone... The rights to positive state actions have been a central and indispensable element of this development. Our view will be focused on them») pero deja nuevamente en la penumbra si para ALEXY estos problemas son específicos de los derechos económico-sociales (los derechos a prestaciones en sentido estricto) o comunes a todo tipo de derechos lo que, de acuerdo con sus propios argumentos, cabría concluir.

La teoría de los derechos fundamentales de ALEXY contiene, en mi opinión, todos los elementos necesarios para concluir, con Holmes y SUNSTEIN, que «todos los derechos legalmente protegidos son necesariamente derechos a acciones positivas» (HOLMES y SUNSTEIN, 1999: 43) ${ }^{30}$. Pero me parece que ALEXY no llega a extraer todas las consecuencias que de ello se derivan. La principal es que hemos de abandonar la distinción histórico-ideológica entre derechos individuales, civiles y políticos, de un lado, y derechos económicos, sociales y culturales, del otro. La teoría de los derechos humanos ha de construirse, por el contrario, a partir de la combinación de dos entradas: por un lado, la distinción entre derechos-libertad, derechos-inmunidad, derechos-pretensión y derechos-potestad y, por el otro, la distinción entre las formas de satisfacción, protección y promoción de los derechos.

\section{BIBLIOGRAFÍA CITADA}

ABramovich, V., y CouRTis, C., 2002: Los derechos sociales como derechos exigibles, Madrid: Trotta. AleXY, R., 1993: Teoría de los derechos fundamentales, Madrid: Centro de Estudios Constitucionales (Orig: Theorie der Grundrechte, Frankfurt/Main: Suhrkamp, 1986).

- 2004: Epílogo a la «Teoría de los Derechos Fundamentales», Madrid: Centro de Estudios del Colegio de Registradores de la Propiedad, Mercantiles y Bienes Muebles de España [Orig: publicado originalmente como epílogo a la traducción inglesa de Theorie der Grundrechte (A Theory of Constitutional Rights, Oxford: Oxford University Press, 2002); publicado en traducción castellana de BERNAL, C. en la Revista Española de Derechos Constitucional, n. ${ }^{\circ}$ 66, 2002, pp. 13-64].

- 2005: On Constitutional Rights to Protection, inédito.

ATIENZA, M., 1983: Marx y los derechos humanos, Madrid: Editorial Mezquita.

AtRIA, F., 2005: «¿Existen derechos sociales?», Discusiones, n. ${ }^{\circ}$ 4, pp. 15-59.

Betegón, J.; Laporta, F. J.; PÁramo, J. R. DE, y PRieto, L. (eds.), 2004: Constitución y derechos fundamentales, Madrid: Centro de Estudios Políticos y Constitucionales.

BLOCH, E., 1980: Derecho natural y dignidad humana, Madrid: Aguilar (Orig: Naturrecht und menschliche würde, Frankfurt/Main: Suhrkamp, 1961).

Cascajo, J. L., 1988: La tutela constitucional de los derechos sociales, Madrid: Centro de Estudios Constitucionales.

CASSESE, A., 1991: Los derechos bumanos en el mundo contemporáneo, Barcelona: Ariel (Orig: I diritti umani nel mondo contemporaneo, Roma-Bari: Laterza \& Figli Spa, 1988).

Contreras Peláez, F. J., 1994: Derechos sociales: teoría e ideología, Madrid: Tecnos.

${ }^{30} \mathrm{El}$ texto original dice «What it shows is that all legally enforced rights are necessarily positive rights». Traduzco «derechos a acciones positivas» porque el mero calificativo «positivos» se ofrecería a confusión en el uso castellano del término y, al mismo tiempo, la traducción resulta fiel al sentido original. 
DíAz, E., y Colomer, J. L., 2002: Estado, justicia, derechos, Madrid: Alianza.

EIDE, A., 2001: Economic, Social and Cultural Rights as Human Rights, en EIDE, Krause y RoSAS, 2001: pp. 9-28.

Eide, A.; Krause, C., y Rosas, A., 2001: Economic, Social and Cultural Rights, Dordrecht: Martinus Nijhoff.

FeInberg, J., 1980: Rights, Justice and the Bounds of Liberty, Princeton (New Jersey): Princeton University Press.

Fernández Almagro, M., 1928: Orígenes del Régimen Constitucional en España, Barcelona: Labor.

GEWIRTH, A., 1984: Are there any Absolute Rights?, en WALDRON, 1995: pp. 91-109.

Hierro, L. L., 1982: «¿Derechos humanos o necesidades humanas? Problemas de un concepto», Sistema, n. ${ }^{\circ} 46$, pp. 45-61.

- 2002: El concepto de justicia y la teoría de los derechos, en DíAz y COLOMER (eds.), pp. 11-73.

- 2002b: Justicia, Igualdad y Eficiencia, Madrid: Centro de Estudios Constitucionales.

- 2003: «Igualdad, generalidad, razonabilidad y crisis de la ley», DOXA. Cuadernos de Filosofía del Derecho, n. ${ }^{\circ} 26$, pp. 449-476.

Holmes, S., y Sunstein, C. R., 1999: The Cost of Rights. Why Liberty Depends on Taxes, New York, W. W. Norton \& Co.

LAPORTA, F. J., 1987: «Sobre el concepto de derechos humanos», DOXA. Cuadernos de Filosofía del Derecho, n. ${ }^{\circ}$ 4, pp. 23-46.

- 2004: Los derechos sociales y su protección jurídica: Introducción al problema, en BETEGÓN, LAPORTA, PÁRAmo y Prieto (eds.), pp. 297-325.

Liebenberg, S., 2001: The Protection of Economic and Social Rights in Domestic Legal Systems, en Eide, Krause y Rosas, pp. 55-84.

MacCormick, N., 1990: Derecho legal y socialdemocracia. Ensayos sobre filosofía jurídica y politica, Madrid: Tecnos (Orig.: Legal Right and Social Democracy, Oxford: Oxford University Press, 1982).

Peces Barba, G., 1999: Derechos sociales y positivismo jurídico (Escritos de filosofía jurídica y política), Madrid: Universidad Carlos III-Dykinson.

Pérez Luño, A. E., 2003: Derechos bumanos, Estado de Derecho y Constitución, Madrid: Tecnos (8. ${ }^{\mathrm{a}}$ ed.).

PRIETO, L., 1998: Ley, principios, derechos, Madrid: Universidad Carlos III-Dykinson.

Ritchie, D. G., 1924: Natural Rights. A Criticism of some Political and Ethical Conceptions, London: George Allen \& Unwin (tercera reimpresión, original de 1894).

Ruiz Miguel, A., 1994: «Derechos liberales y derechos sociales», DOXA. Cuadernos de Filosofia del Derecho, n. ${ }^{\text {os } 15-16, ~ p p . ~ 651-674 . ~}$

SCANLON, T. M., 1984: Rights, Goals, and Fairness, en WALDRON, 1995: pp. 137-152.

SCHEININ, M., 2001: Economic and Social Rights as Legal Rights, en EIDE, KraUSE y RosaS, pp. 29-54.

WaldRON, J. (ed.), 1995: Theories of Rights, Oxford: Oxford University Press.

Wellman, C., 1997: An Approach to Rights. Studies in the Philosophy of Law and Morals, Dordrecht: Kluwer.

Westen, P., 1990: Speaking of Equality. An Analysis of the Rethorical Force of «Equality» in Moral and Legal Discourse, Princeton (New Jersey): Princeton University Press. 